\title{
Syntheses and characterization of two novel 1D Pb(II) Halide supramolecular polymers possessing incomplete Cubane subunit directed by $\pi$-conjugated Dication templates
}

\author{
CHENGJIE MA ${ }^{\mathrm{a}}$, MEI LIU ${ }^{\mathrm{b}}$, WENLI ZHANG ${ }^{\mathrm{a}}$, HAIJUAN DU $^{\mathrm{a}}$, YAO LI $^{\mathrm{a}}, \mathrm{CHAOHAI} \mathrm{WANG}^{\mathrm{a}}$ \\ and YUNYIN NIU ${ }^{\mathrm{a}, *}$ \\ ${ }^{a}$ College of Chemistry and Molecular Engineering, Zhengzhou University, Zhengzhou 450001, P. R. China \\ ${ }^{b}$ Physical, Chemical and Biological Department, Henan Jiaozuo Teacher's College, Jiaozuo 454000, P. R. \\ China \\ e-mail: niuyy@zzu.edu.cn
}

MS received 26 January 2015; revised 25 March 2015; accepted 28 March 2015

\begin{abstract}
Two novel cation-templated complexes, $\left\{(1,4-\mathrm{PMBP})\left[\mathrm{Pb}_{4} \mathrm{I}_{10}\right] \cdot \mathrm{DMF}\right\}_{\mathrm{n}}(\mathbf{1})\left\{(\mathrm{DBBP})_{2}\left[\mathrm{~Pb}_{5} \mathrm{I}_{8} \mathrm{Br}_{6}\right]\right\}$ n (2), (1,4-PMBP-2Br =1,1"'-[1,4-phenylene-bis(methylene)]bis-4,4'-bipyridinium dibromide; $\mathrm{DBBP} \cdot 2 \mathrm{Br}=\mathrm{N}$, N'-dibenzyl- 4, 4'-bipyridinium dibromide) have been synthesized via the self-assembly reaction in solution. $\mathrm{X}$-ray crystallography showed that compounds $\mathbf{1}$ and $\mathbf{2}$ can be regarded as 1D iodoplumbate examples which contain incomplete cubane subunit directed by $\pi$-conjugated dication templates. It is the H-bonds and electrostatic interactions between the organic counter cations and inorganic moieties that contribute the crystal packing. These compounds have been further characterized by IR spectroscopy, UV-Vis spectra, elemental analysis and thermostability properties.
\end{abstract}

Keywords. $\pi$-conjugated cation templates; iodoplumbates hybrids; inorganic/organic interactions.

\section{Introduction}

In the last decade, template-oriented organic-inorganic hybrid materials have gradually become one of the most actively explored area of chemical engineering and molecular science because of their fascinating crystal structures and potential applications in photochromism, electrical conductivity, biology, catalysis, etc. ${ }^{1-5}$ More and more attention has been drawn to this domain not only because of the opportunity to combine the distinctive properties of both inorganic and organic components in one material, ${ }^{6}$ but also because of the possibility of producing novel properties by the synergetic interactions between two counter components. ${ }^{7}$

Among the various families of inorganic-organic hybrid polymers, haloplumbates are an important family of hybrid functional materials. ${ }^{8}$ The compounds have been reported to exhibit rich anion structures, including discrete 0-D oligomers: mononuclear $\left(\mathrm{PbI}_{4}\right)^{2-}$, binuclear $\left(\mathrm{Pb}_{2} \mathrm{I}_{6}\right)^{2-}$, trinuclear $\left(\mathrm{Pb}_{3} \mathrm{I}_{10}\right)^{4-}$, pentanuclear $\left(\mathrm{Pb}_{5} \mathrm{I}_{16}\right)^{6-}$, hexanuclear $\left(\mathrm{Pb}_{6} \mathrm{I}_{22}\right)^{10-}$, heptanuclear $\left(\mathrm{Pb}_{7} \mathrm{I}_{22}\right)^{8-}$, decanuclear $\left(\mathrm{Pb}_{10} \mathrm{I}_{28}\right)^{8-}$, and octadecanuclear $\left(\mathrm{Pb}_{18} \mathrm{I}_{44}\right)^{8-}$ clusters $;{ }^{9-13}$ 1-D chains $\left(\mathrm{PbI}_{5}\right)^{3-}$, $\left(\mathrm{Pb}_{2} \mathrm{I}_{6}\right)^{2-}$, and $\left(\mathrm{Pb}_{2} \mathrm{Cl}_{2} \mathrm{I}_{4}\right)^{2-} ;{ }^{14-17}$ 2-D layers $\left(\mathrm{PbI}_{4}\right)^{2-}$,

*For correspondence
$\left(\mathrm{PbCl}_{4}\right)^{2-},\left(\mathrm{PbCl}_{3}\right)^{18-20}$ and 3-D frameworks $\left[\mathrm{Pb}_{7} \mathrm{I}_{18}\right]^{2 \mathrm{n}-}$ and $\left[\mathrm{Pb}_{15} \mathrm{I}_{34}(\mathrm{dmf})_{6}\right]^{4-} \cdot{ }^{21}$

The structural diversity of the haloplumbate-based hybrid is due to two factors: (i) the coordination number of $\mathrm{Pb}^{2+}$ ion ranges from 4 to 8 and its coordination geometry can be distorted tetrahedron, square pyramid, octahedron, triangular prism, monocapped octahedron or bicapped octahedron and so on. ${ }^{22-24}$ (ii) stepwise aggregations of the building units with the above-mentioned coordination geometry give rise to various anionic structural motif, via sharing of $\mathrm{X}-\mathrm{X}-\mathrm{X}$ triangular faces, $\mathrm{X}-\mathrm{X}$ edges or $\mathrm{X}$ apexes $\left(\mathrm{X}^{-}=\mathrm{Cl}^{-}\right.$, $\mathrm{Br}^{-}$or $\mathrm{I}^{-}$ion) of the adjacent coordination polyhedra, from the mononuclear or polynuclear species to higher dimensionality. However, the synthesis of compounds directed by $\pi$-conjugated $\mathrm{N}$-containing organic dication templates are rarely reported..$^{25}$ On the basis of our previous work, subtle changes of the organic cationic properties, such as size, shape, and distribution of the positive charge, may lead to diverse aggregates of haloplumbate. ${ }^{26}$ Recently, we found that $\pi$-conjugated 4,4'-bipyridine derivative dication possesses the ideal size for structure-directing for construction of the organic-inorganic hybrid polymers. So in this contribution, we have selected two new cation-templates (scheme 1) and successfully 


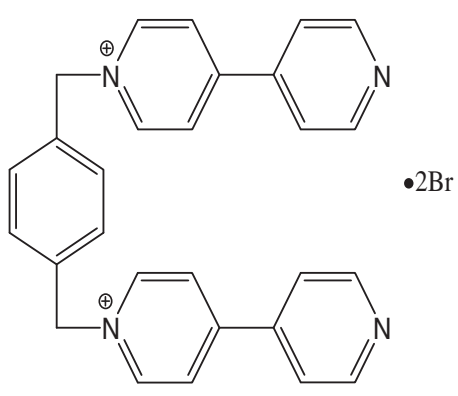

(a)

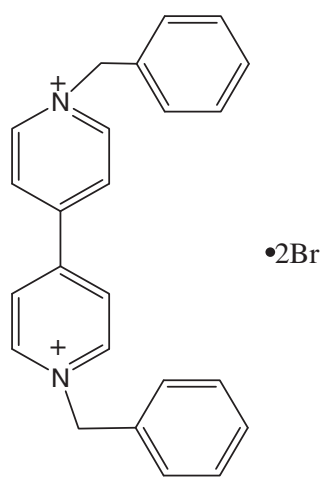

(b)
Scheme 1. The molecular structure of the dications (a) 1, 4-PMBP.2Br, (b) DBBP.2Br.

synthesized two novel complexes which contain incomplete subunit, $\left\{(1,4-\mathrm{PMBP})\left[\mathrm{Pb}_{4} \mathrm{I}_{10}\right] \cdot \mathrm{DMF}\right\}_{\mathrm{n}}(\mathbf{1})\{(\mathrm{DBB}$ $\left.\mathrm{P})_{2}\left[\mathrm{~Pb}_{5} \mathrm{I}_{8} \mathrm{Br}_{6}\right]\right\}_{\mathrm{n}}(2),(1,4-\mathrm{PMBP} \cdot 2 \mathrm{Br}=1,1$ "'-[1,4-phenylene-bis(methylene)]bis-4,4'-bipyridinium dibromide; DBBP.2Br $=\mathrm{N}$, N'-dibenzyl- 4, 4'-bipyridinium dibromide). To the best of our knowledge, compounds $\mathbf{1}$ and $\mathbf{2}$ can be regarded as 1D iodoplumbate examples which contain incomplete cubane subunits. We have also investigated the thermal behavior and optical properties.

\section{Experimental}

\subsection{Materials and Instruments}

All chemicals and solvents were of A.R. grade and used without further purification. The FT-IR spectra were recorded from $\mathrm{KBr}$ pellets in the range from 4000 to $400 \mathrm{~cm}^{-1}$ on a Bruker VECTOR 22 spectrometer. Elemental analysis was carried out on a Vario EL III elemental analyzer( $\mathrm{C}, \mathrm{H}$ and $\mathrm{N})$. Thermal analyses were performed on a SDT 2960 thermal analyzer from room temperature to $800^{\circ} \mathrm{C}$ at a heating rate of $5^{\circ} \mathrm{C} \mathrm{min}{ }^{-1}$ under air flow. Powder X-ray diffraction $(\mathrm{Cu} \mathrm{K} \alpha$ radiation, $\lambda=1.5418 \AA$ A 5.08 second per step, $293 \mathrm{~K}$ ) patterns were collected on an X'Pert PRO diffractometer in the scan range of $5-70^{\circ}$. The UV-Vis diffuse reflectance spectra (DRS) were taken on a Cary 5000 UVVis-NIR spectrophotometer with $\mathrm{BaSO}_{4}$ as reference from 800 to $200 \mathrm{~nm}$. The absorption spectra were calculated from reflectance spectra using the KubelkaMunk function: $\alpha / \mathrm{S}=(1-\mathrm{R})^{2} / 2 \mathrm{R}$, where $\alpha$ is the absorption coefficient, $\mathrm{S}$ is the scattering coefficient (which is practically wavelength independent when the particle size was larger than $5 \mu \mathrm{m}$ ), and $\mathrm{R}$ is the reflectance.

Table 1. Crystal data and structure refinement details for $\mathbf{1}$ and $\mathbf{2}$.

\begin{tabular}{|c|c|c|}
\hline Complexes & 1 & 2 \\
\hline Empirical formula & $\mathrm{C}_{31} \mathrm{H}_{31} \mathrm{I}_{6} \mathrm{~N}_{5} \mathrm{OPb}_{2}$ & $\mathrm{C}_{48} \mathrm{H}_{44} \mathrm{Br}_{6} \mathrm{I}_{8} \mathrm{~N}_{4} \mathrm{~Pb}_{5}$ \\
\hline Formula weight & 1665.39 & 3207.48 \\
\hline Crystal system & monoclinic & monoclinic \\
\hline Space group & $\mathrm{P} 21$ & $\mathrm{C} 2 / \mathrm{c}$ \\
\hline$a / \AA$ & 4.59957(9) & $27.769(3)$ \\
\hline$b / \AA$ & $19.5863(4)$ & 21.1463(8) \\
\hline$c / \AA ̊$ & $21.8372(4)$ & $15.4603(14)$ \\
\hline$\alpha\left({ }^{\circ}\right)$ & 90.00 & 90.00 \\
\hline$\beta\left(^{\circ}\right)$ & $95.1329(17)$ & $130.086(15)$ \\
\hline$\gamma\left({ }^{\circ}\right)$ & 90.00 & 90.00 \\
\hline$V / \AA^{3}$ & $1959.39(6)$ & $6945.9(9)$ \\
\hline Z & 2 & 4 \\
\hline$\rho / \mathrm{Mg} \mathrm{cm}^{-3}$ & 2.823 & 3.067 \\
\hline$\mu / \mathrm{mm}^{-1}$ & 53.87 & 55.310 \\
\hline$F(000)$ & 1484.0 & 5616.0 \\
\hline Crystal size/mm & $0.18 \times 0.12 \times 0.06$ & $0.26 \times 0.07 \times 0.05$ \\
\hline$T / \mathrm{K}$ & 291.15 & 291.15 \\
\hline Reflections collected & 14447 & 12898 \\
\hline Independent reflections & $7378\left[\mathrm{R}_{\int}=0.0380, \mathrm{R}_{\text {sigma }}=0.0549\right]$ & $6215\left[\mathrm{R}_{f}=0.0423, \mathrm{R}_{\text {sigma }}=0.0481\right]$ \\
\hline data/restrains/parameters & $7378 / 3 / 408$ & $6215 / 0 / 321$ \\
\hline GOF on $F^{2}$ & 1.037 & 1.036 \\
\hline Final $\mathrm{R}$ indices $[\mathrm{I}>2 \sigma(\mathrm{I})]$ & $\mathrm{R}_{1}=0.0474, \mathrm{wR}_{2}=0.1174$ & $\mathrm{R}_{1}=0.0634, \mathrm{wR}_{2}=0.1734$ \\
\hline $\mathrm{R}$ indices (all data) & $\mathrm{R}_{1}=0.0559, \mathrm{wR}_{2}=0.1261$ & $\mathrm{R}_{1}=0.0742, \mathrm{wR}_{2}=0.1873$ \\
\hline Largest diff. peak & 1.80 & 2.81 \\
\hline hole $\left(\mathrm{e}^{-3}\right)$ & -1.16 & -1.32 \\
\hline
\end{tabular}




\subsection{Organic cation template syntheses}

2.2a Synthesis of 1,4-PMBP.2Br: 1,4-PMBP.2Br was prepared by direct alkylation of 4,4 '-dipyridine with 1, 4-bis(bromomethyl)benzene which were refluxed at $85^{\circ}$ for $24 \mathrm{~h}$ (acetonitrile served as the solvent for the reaction). ${ }^{27} \mathrm{~A}$ brown precipitate was obtained and the reaction mixture was cooled to room temperature. It was then filtered off and washed with acetonitrile, and dried under vacuum. Brown powder was obtained in $57 \%$ yield.

$2.2 \mathrm{~b}$ Synthesis of DBBP.2Br: DBBP. $2 \mathrm{Br}$ was prepared through Menshutkin reaction by heating the mixture of 4,4-bipyridine $(3.0 \mathrm{mmol})$ and benzyl bromide $(8.3 \mathrm{mmol})$ in dry DMF $(10 \mathrm{~mL})$ under $\mathrm{N}_{2}$ gas atmosphere $\left(70^{\circ} \mathrm{C}, 24 \mathrm{~h}\right)$. Resulting precipitate was washed with acetone and recrystallized from ethanol to obtain the product as yellow crystals with $84 \%$ yield. ${ }^{28}$
2.3 Synthesis of compounds $\{(1,4-P M B P)$

$\left.\left[P b_{4} I_{10}\right] \cdot D M F\right\}_{n}(1)$ and $\left\{(D B B P)_{2}\left[P b_{5} I_{8} B r_{6}\right]\right\}_{n}$

Compounds $\mathbf{1}$ and $\mathbf{2}$ were synthesized similarly. A methanol solution $(0.5 \mathrm{~mL})$ of 1 , 4-PMBP. $2 \mathrm{Br}$ or DBBP.2Br (0.05 mmol) was added into a stirring light yellow solution of $\mathrm{PbI}_{2}(0.05 \mathrm{mmol})$ dissolved in 5.0 $\mathrm{mL} \mathrm{DMF} / \mathrm{H} 2 \mathrm{O}$ with excess $\mathrm{KI}(0.25 \mathrm{mmol})$. The precipitate formed was dissolved by adding more DMF $(5 \mathrm{~mL})$ until the precipitate disappeared. The yellowish solution was filtered and slowly evaporated in a vial at room temperature. Two months later, red crystals suitable for X-ray analysis were obtained in about $48 \%$ yield (for 1) and $72 \%$ (for 2 ) based on lead ion.

IR $\left(\mathrm{KBr}, \mathrm{cm}^{-1}\right)$ for 1: 3441.34(m), 3019.80(w), 2922.11(w), 2160.92(w), 1647.45(s), 1630.41(s), 1541.65(m), 1522.00(w), 1487.81(w), 1462.74(w), 1428.71(w), $1405.00(\mathrm{~m}), \quad 1384.03(\mathrm{~m}), 1345.74(\mathrm{w})$, 1284.54(w), 1239.18(w), 1216.49(w), 1161.15(w),

Table 2. Selected bonds distances $(\AA)$ and angles $\left(^{\circ}\right)$ for compounds $\mathbf{1}$ and $\mathbf{2}$.

\begin{tabular}{|c|c|c|c|c|c|}
\hline \multicolumn{6}{|l|}{1} \\
\hline Pb1-I1 & $3.085(1)$ & $\mathrm{Pb} 1-\mathrm{I} 2$ & $3.296(1)$ & $\mathrm{Pb} 1-\mathrm{I} 2^{1}$ & $3.237(1)$ \\
\hline $\mathrm{Pb} 1-\mathrm{I}^{1}$ & $3.223(1)$ & $\mathrm{Pb} 1-\mathrm{I} 3$ & $3.162(1)$ & $\mathrm{Pb} 1-\mathrm{I} 4$ & $3.405(1)$ \\
\hline $\mathrm{Pb} 2-\mathrm{I} 4$ & $3.257(1)$ & $\mathrm{Pb} 2-\mathrm{I}^{2}$ & $3.310(1)$ & $\mathrm{Pb} 2-\mathrm{I} 5$ & $3.207(1)$ \\
\hline $\mathrm{Pb} 2-\mathrm{I}^{2}$ & $3.201(1)$ & Pb2-I6 & $2.968(1)$ & $\mathrm{Pb}^{2}-\mathrm{I} 2$ & $3.237(1)$ \\
\hline $\mathrm{Pb}^{2}-\mathrm{I} 3$ & $3.223(1)$ & $\mathrm{Pb} 2^{1}-\mathrm{I} 4$ & $3.310(1)$ & $\mathrm{Pb} 2^{1}-\mathrm{I} 5$ & $3.201(1)$ \\
\hline $\mathrm{I} 1-\mathrm{Pb} 1-\mathrm{I} 2$ & $93.68(3)$ & $\mathrm{I} 1-\mathrm{Pb} 1-\mathrm{I} 2^{1}$ & $94.76(3)$ & $\mathrm{I} 1-\mathrm{Pb} 1-\mathrm{I} 3^{1}$ & $88.42(3)$ \\
\hline I1-Pb1-I3 & $87.36(3)$ & I1-Pb1-I4 & 169.61(3) & $\mathrm{I} 2^{1}-\mathrm{Pb} 1-\mathrm{I} 2$ & $89.48(3)$ \\
\hline $\mathrm{I} 2^{1}-\mathrm{Pb} 1-\mathrm{I} 4$ & $90.70(3)$ & I2-Pb1-I4 & $95.21(3)$ & $\mathrm{I}^{1}-\mathrm{Pb} 1-\mathrm{I} 2$ & $177.57(3)$ \\
\hline $\mathrm{I} 3-\mathrm{Pb} 1-\mathrm{I} 2$ & $89.16(3)$ & $\mathrm{I} 3-\mathrm{Pb} 1-\mathrm{I} 2^{1}$ & $177.55(3)$ & $\mathrm{I} 3^{1}-\mathrm{Pb} 1-\mathrm{I} 2^{1}$ & $89.13(3)$ \\
\hline $\mathrm{I} 3-\mathrm{Pb} 1-\mathrm{I} 3^{1}$ & $92.15(3)$ & I3- Pb1-I4 & $87.40(3)$ & I3 ${ }^{1}-\mathrm{Pb} 1-\mathrm{I} 4$ & $82.82(3)$ \\
\hline $\mathrm{I} 4-\mathrm{Pb} 2-\mathrm{I}^{2}$ & $88.90(3)$ & $\mathrm{I}^{2}-\mathrm{Pb} 2-\mathrm{I} 4$ & $166.33(3)$ & $\mathrm{I} 5-\mathrm{Pb} 2-\mathrm{I} 4^{2}$ & $166.54(3)$ \\
\hline $\mathrm{I} 5-\mathrm{Pb} 2-\mathrm{I} 4$ & $88.50(3)$ & $\mathrm{I}^{2}-\mathrm{Pb} 2-\mathrm{I} 4^{2}$ & $87.70(3)$ & $\mathrm{I}^{2}-\mathrm{Pb} 2-\mathrm{I} 5$ & $91.74(3)$ \\
\hline $\mathrm{I} 6-\mathrm{Pb} 2-\mathrm{I}^{2}$ & $98.87(4)$ & I6-Pb2-I4 & $98.17(4)$ & I6-Pb2-I5 ${ }^{2}$ & $95.43(4)$ \\
\hline I6-Pb2-I5 & $94.57(4)$ & & & & \\
\hline \multicolumn{6}{|l|}{2} \\
\hline $\mathrm{Pb} 1-\mathrm{I}^{1}$ & $3.327(1)$ & Pb1-I1 & $3.327(1)$ & $\mathrm{Pb} 1-\mathrm{I} 2^{1}$ & $3.210(1)$ \\
\hline $\mathrm{Pb} 1-\mathrm{I} 2$ & $3.210(1)$ & $\mathrm{Pb} 1-\mathrm{I}^{2}$ & $3.158(1)$ & $\mathrm{Pb} 1-\mathrm{I}^{3}$ & $3.158(1)$ \\
\hline $\mathrm{Pb} 2-\mathrm{I}^{2}$ & $3.336(1)$ & $\mathrm{Pb} 2-\mathrm{I} 2$ & $3.199(1)$ & Pb2-I3 & $3.214(1)$ \\
\hline $\mathrm{Pb} 2-\mathrm{I} 4$ & $3.148(1)$ & Pb2-Br1 & $2.936(1)$ & $\mathrm{Pb} 3-\mathrm{I}^{4}$ & $3.249(1)$ \\
\hline Pb3-Br1 & $3.103(1)$ & $\mathrm{Pb} 3-\mathrm{Br} 2$ & $2.772(2)$ & Pb3-Br3 & $2.855(1)$ \\
\hline $\mathrm{Pb}^{2}-\mathrm{I} 1$ & $3.336(1)$ & $\mathrm{Pb} 1^{2}-\mathrm{I} 3$ & $3.158(1)$ & $\mathrm{Pb}^{3}-\mathrm{I} 4$ & $3.249(1)$ \\
\hline I1-Pb1-I1 ${ }^{1}$ & $84.77(4)$ & $\mathrm{I} 2^{1}-\mathrm{Pb} 1-\mathrm{I} 1$ & $94.29(3)$ & I2-Pb1-I1 & $86.62(3)$ \\
\hline I2-Pb1-I1 ${ }^{1}$ & $94.29(3)$ & $\mathrm{I} 2^{1}-\mathrm{Pb} 1-\mathrm{I} 1^{1}$ & $86.63(3)$ & $\mathrm{I} 2^{1}-\mathrm{Pb} 1-\mathrm{I} 2$ & $178.77(5)$ \\
\hline $\mathrm{I}^{2}-\mathrm{Pb} 1-\mathrm{I} 1$ & $171.73(3)$ & $\mathrm{I}^{2}-\mathrm{Pb} 1-\mathrm{I} 1^{1}$ & $92.25(3)$ & $\mathrm{I}^{3}-\mathrm{Pb} 1-\mathrm{I} 1^{1}$ & $171.73(3)$ \\
\hline $\mathrm{I}^{3}-\mathrm{Pb} 1-\mathrm{I} 1$ & $92.25(3)$ & $\mathrm{I}^{2}-\mathrm{Pb} 1-\mathrm{I} 2$ & $85.91(3)$ & $\mathrm{I}^{2}-\mathrm{Pb} 1-\mathrm{I} 2^{1}$ & $93.23(3)$ \\
\hline $\mathrm{I} 3^{3}-\mathrm{Pb} 1-\mathrm{I} 2$ & $93.23(3)$ & $\mathrm{I}^{3}-\mathrm{Pb} 1-\mathrm{I} 2^{1}$ & $85.91(3)$ & $\mathrm{I}^{2}-\mathrm{Pb} 1-\mathrm{I}^{3}$ & $91.71(4)$ \\
\hline $\mathrm{I} 2-\mathrm{Pb} 2-\mathrm{I}^{3}$ & $87.72(3)$ & $\mathrm{I} 2-\mathrm{Pb} 2-\mathrm{I} 3$ & $176.68(3)$ & $\mathrm{I} 3-\mathrm{Pb} 2-\mathrm{I}^{3}$ & $91.10(3)$ \\
\hline $\mathrm{I} 4-\mathrm{Pb} 2-\mathrm{I} 1^{3}$ & $173.60(3)$ & $\mathrm{I} 4-\mathrm{Pb} 2-\mathrm{I} 2$ & $94.33(3)$ & $\mathrm{I} 4-\mathrm{Pb} 2-\mathrm{I} 3$ & $87.18(3)$ \\
\hline $\mathrm{Br} 1-\mathrm{Pb} 2-\mathrm{I}^{3}$ & $86.56(4)$ & $\mathrm{Br} 1-\mathrm{Pb} 2-\mathrm{I} 2$ & $89.85(4)$ & $\mathrm{Br} 1-\mathrm{Pb} 2-\mathrm{I} 3$ & $93.17(4)$ \\
\hline Br1-Pb2-I4 & $87.38(4)$ & $\mathrm{Br} 1-\mathrm{Pb} 3-\mathrm{I} 4^{4}$ & $172.25(4)$ & $\mathrm{Br} 2-\mathrm{Pb} 3-\mathrm{I} 4^{4}$ & $92.29(5)$ \\
\hline $\mathrm{Br} 2-\mathrm{Pb} 3-\mathrm{Br} 1$ & $95.41(5)$ & $\mathrm{Br} 2-\mathrm{Pb} 3-\mathrm{Br} 3$ & $88.09(6)$ & $\mathrm{Br} 3-\mathrm{Pb} 3-\mathrm{I} 4^{4}$ & $91.96(5)$ \\
\hline Br3-Pb3-Br1 & 87.39(4) & & & & \\
\hline
\end{tabular}

symmetry codes: ${ }^{1}-1+\mathrm{X},+\mathrm{Y},+\mathrm{Z} ;{ }^{2} 1+\mathrm{X},+\mathrm{Y},+\mathrm{Z}$ for $\mathbf{1} ;{ }^{1}-\mathrm{X},+\mathrm{Y},-1 / 2-\mathrm{Z} ;{ }^{2}-\mathrm{X}, 1-\mathrm{Y},-\mathrm{Z} ;{ }^{3}+\mathrm{X}, 1-\mathrm{Y},-1 / 2+\mathrm{Z} ;{ }^{4}+\mathrm{X}, 1-\mathrm{Y}, 1 / 2+\mathrm{Z} ;{ }^{5} 1 / 2-$ $\mathrm{X}, 1 / 2-\mathrm{Y}, \mathrm{Z} ;{ }^{6} 1-\mathrm{X},+\mathrm{Y}, 1 / 2-\mathrm{Z}$ for 2. 
1099.93(w), $\quad 1069.56(\mathrm{w}), \quad 882.47(\mathrm{w}), \quad 813.11(\mathrm{~m})$, 767.20(w), 729.30(w), 711.34(w), 622.68(w), 604.12(w), 599.69(w), 512.59(w). Anal. Calcd for $\mathrm{C}_{31} \mathrm{H}_{31} \mathrm{I}_{6} \mathrm{~N}_{5} \mathrm{OPb}_{2}$ : C 22.36, H 1.88, N 4.21\%. Found: $\mathrm{C}$ 22.18, H 1.76, N 4.11\%.

IR $\left(\mathrm{KBr}, \mathrm{cm}^{-1}\right)$ for 2: 3442.59(s), 3107.81(w), 3042.11(w), 2924.18(w), 2363.33(w), 2169.50(w), 1735.11(w), 1718.38(w), 1701.03(w), 1653.91(w), 1629.15(m), $1558.10(\mathrm{w}), \quad 1493.51(\mathrm{w}), \quad 1437.43(\mathrm{w})$, 1384.24(m), 1348.61(w), 1268.25(w), 1208.71(w), 1154.24(w), $\quad 1026.79(\mathrm{w}), \quad 806.23(\mathrm{w}), \quad 742.04(\mathrm{~m})$, 699.79(w). Anal. Calcd for $\mathrm{C}_{48} \mathrm{H}_{44} \mathrm{Br}_{6} \mathrm{I}_{8} \mathrm{~N}_{4} \mathrm{~Pb}_{5}$ : C 17.97, H 1.38, N 1.75\%. Found: C 17.61, H 1.27, N 1.59\%.

\subsection{X-Ray Crystallography}

Crystallographic data for $\mathbf{1}$ and $\mathbf{2}$ were collected at RT on a Bruker APEX-II area detector diffractometer equipped with graphite-monochromated Mo-K $\alpha$ radiation $(\lambda=0.71073 \AA)$. The structures were solved by direct methods and expanded using Fourier techniques. Non-hydrogen atoms were refined with anisotropic thermal parameters. The hydrogen atoms were assigned with common isotropic displacement factors and included in the final refinement by using geometrical constraints. The structures were refined with full-matrix least-squares techniques on F2 using SHELXTL-97. ${ }^{29}$ Crystallographic data and structural refinement details for $\mathbf{1}$ and $\mathbf{2}$ were summarized in table 1. Selected bond lengths and angles of 1-2 were summarized in table 2.

\section{Results and Discussion}

\subsection{Crystal Structures and Characterization}

The X-ray single-crystal structural analysis reveals that compound 1 crystallizes in the monoclinic system with the space group $P 2_{1}$. The asymmetric unit consists of an anion $\left[\mathrm{Pb}_{4} \mathrm{I}_{10}\right]^{2-}$, one $[1,4-\mathrm{PMBP}]^{2+}$ cation and one DMF molecule as shown in figure 1a. Compound 1 exhibits a 1D inorganic open-framework structure, in which an incomplete cubane chain (ICC) acts as the building block of the inorganic framework. There are two crystallographically independent $\mathrm{Pb}$ atoms,

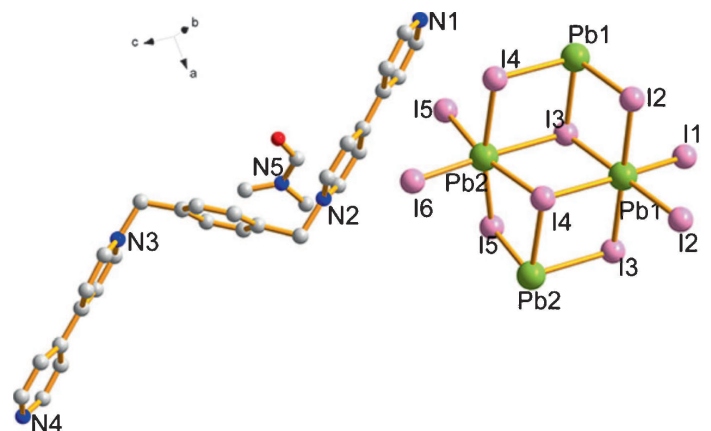

(a)

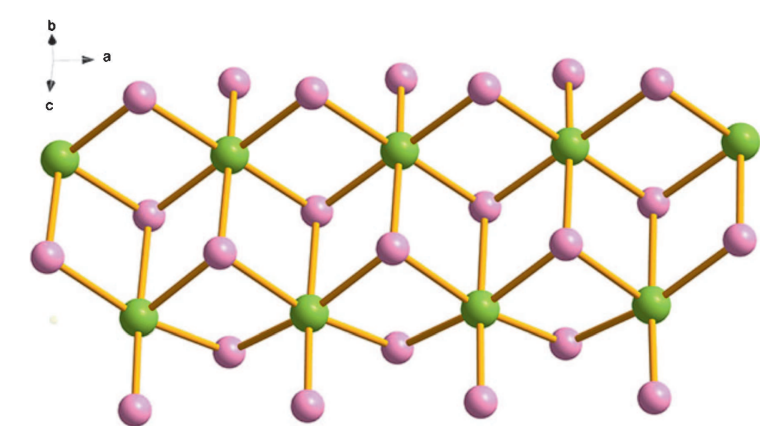

(b)

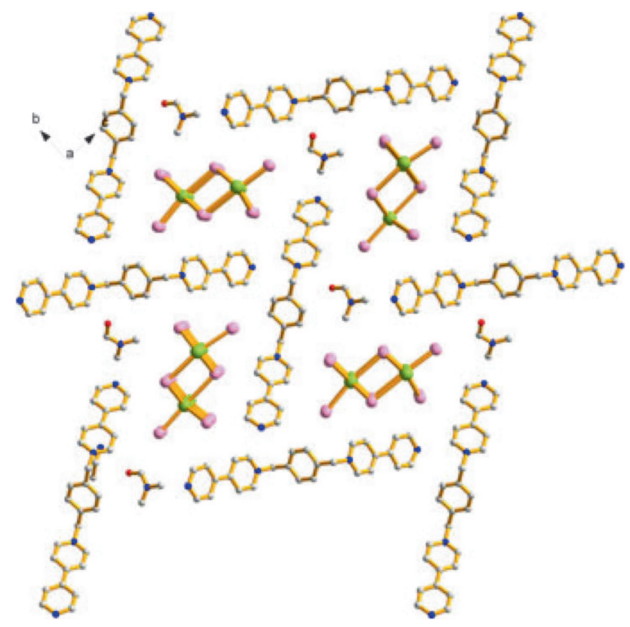

(c)

Figure 1. (a) the structural unit of compound 1; (b) the 1D inorganic chains for compound 1 view along the $b$ axis; (c) The packing diagram of compound $\mathbf{1}$ view along $a$ axis. 
which are all situated in a slightly distorted octahedral coordination environment with bond distances ranging from 2.9687(14) to 3.4059(12) $\AA$ and bond angles ranging from $87.36(3)$ to $177.55(3)^{\circ}$. The incomplete cubane units, composed of edge-sharing $\mathrm{PbI}_{6}$ octahedron centered at $\mathrm{Pb} 1$ and $\mathrm{Pb} 2$, interlink each other through a crystallographic inversion center to form ICCs extending along a axis, in which neighboring incomplete cubanes are further consolidated by $\mathrm{I} 2$ and
I5 atoms as shown in figure $1 \mathrm{~b}$. This ICC is structurally similar to the inorganic chain in the 1D compound $\left(\mathrm{C}_{10} \mathrm{H}_{7} \mathrm{CH}_{2} \mathrm{NH}_{3}\right)_{\mathrm{n}}\left(\mathrm{PbI}_{3}\right)_{\mathrm{n}}(4) .{ }^{30}$ In the packing structure, the polyanionic chains are located in the rhombic cavities formed by dications to maintain the neutrality of the whole crystal. Solvent DMF molecules are located in the voids of the compound. It is electrostatic forces and $\mathrm{C}-\mathrm{H}$...I weak interactions between cations and inorganic chains that pile these components up into a $3 \mathrm{D}$

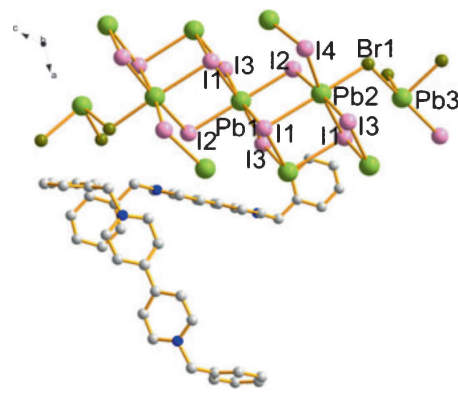

(a)

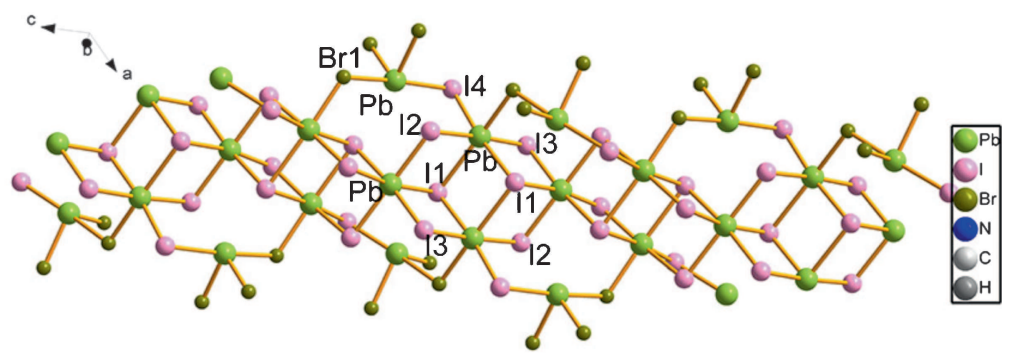

(b)

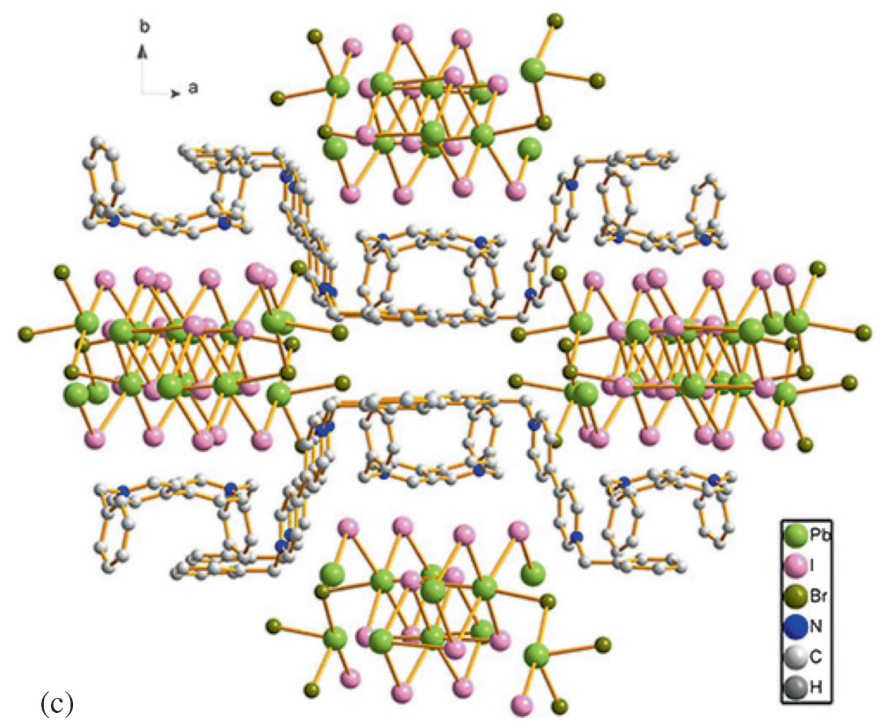

Figure 2. (a) the structural unit of compound 2; (b) the 1D inorganic chains for compound 2; (c) The packing diagram of compound $\mathbf{2}$ view along $c$ axis.
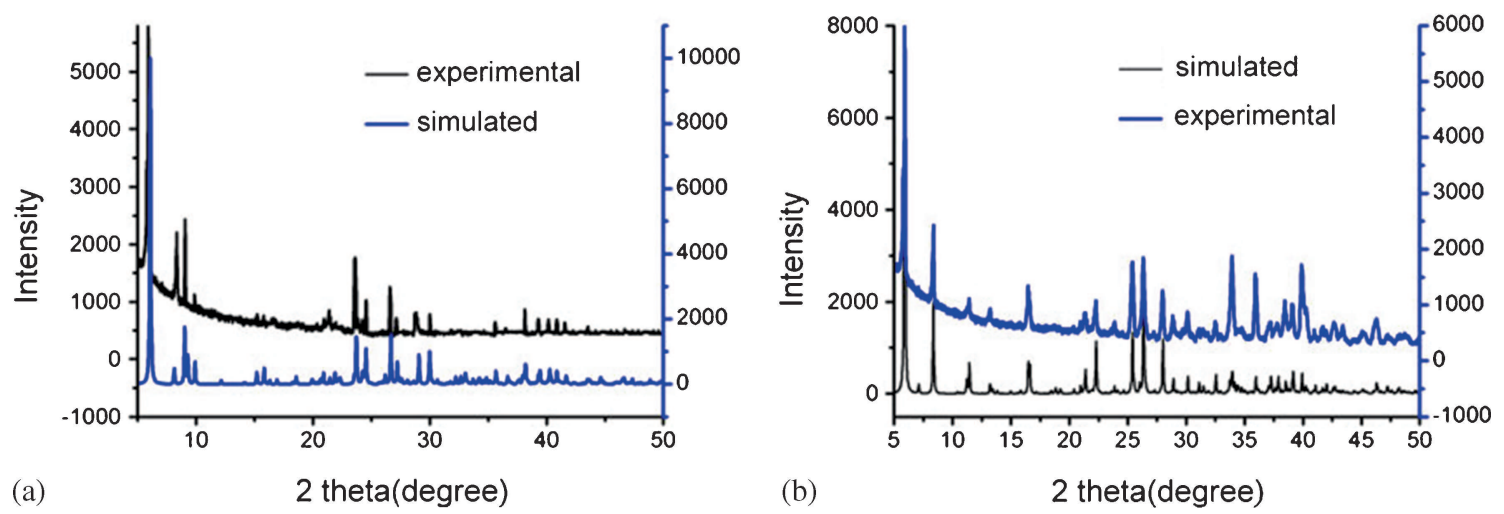

Figure 3. Simulated and experimental PXRD pattern of (a) compound 1, (b) compound 2. 
stacking structure viewing along $a$ axis, as shown in figure 1c.

Compound 2 contains also an incomplete cubane chain (ICC) acting as the building block of the inorganic framework and has only subtle differences in their anionic structure. Compound $\mathbf{2}$ crystallizes in the monoclinic space group $C 2 / c$. As shown in figure $2 \mathrm{a}, \mathrm{Pb}$ center exhibits three coordination modes, the $\mathrm{Pb} 1$ center is six-coordinated in a distorted octahedral geometry by four $\mu_{2}$-I atoms (I2 and I3) and two $\mu_{3}$-I atoms (I1), the $\mathrm{Pb} 2$ center is six-coordinated in a distorted octahedral geometry by three $\mu_{2}$-I atoms (I2, I3 and I4), two $\mu_{3}$-I atoms (I1) and one $\mu_{2}-\mathrm{Br}$ atom, the $\mathrm{Pb} 3$ center is four-coordinated in a distorted tetrahedral geometry by one $\mu_{2}$-I atom (I4), two t-Br atoms $(\mathrm{Br} 2$ and $\mathrm{Br} 3)$ and one $\mu_{2}-\mathrm{Br}$ (Br1)atom. The $\mathrm{Pb}-\mathrm{I}$ distance ranges from 3.1482(11) $\AA$ to 3.3365(11) $\AA$, Pb-Br distance ranges from 2.772(2) $\AA$

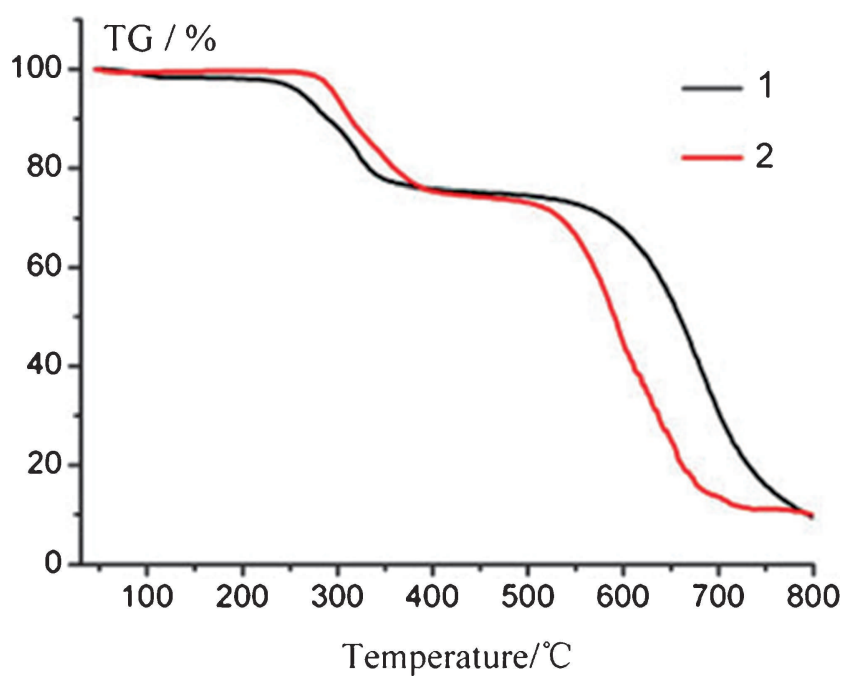

Figure 4. TG plot of compounds $\mathbf{1}$ and $\mathbf{2}$.
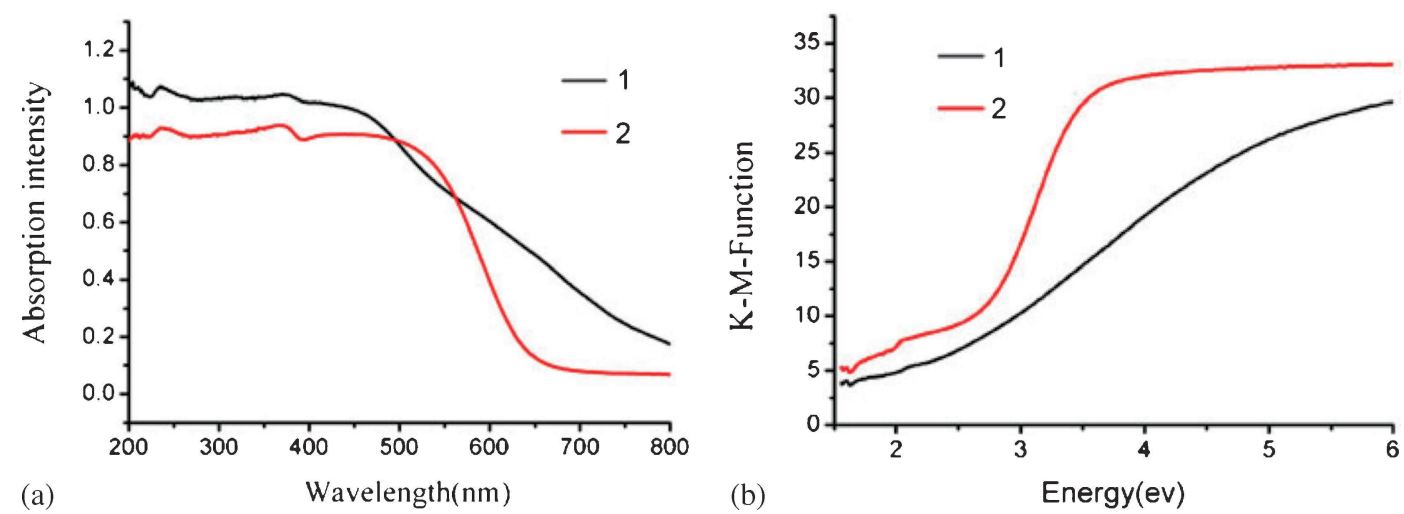

Figure 5. (a) UV-Vis absorption spectrum of $\mathbf{1}$ and $\mathbf{2}$ taken at room temperature; (b) Determination of the optical band gap of $\mathbf{1}$ and $\mathbf{2}$ diffuse reflectance spectrum using the Kubelka-Munk method. to $3.1032(14) \AA$. The I-Pb-I bond angles of all bridging iodo ligands are in the ranges $84.77(4)-94.33(3)^{\circ}$ and 171.73(3)-178.77(5) ${ }^{\circ}$, which deviates from the desired bond angles of octahedra. Two $\mathrm{Pb}(3)$ atoms, two $\mathrm{Pb}(2)$ atoms and one $\mathrm{Pb}(1)$ atom located in a line. This onedimensional chain could be viewed as having two linear $\mathrm{Pb} 5$ fragments which are alternatively stacked by edgesharing along the $c$ axis. The structure of compound $\mathbf{2}$ is similar to the reported compound $\left[\left(\mathrm{Pb}_{5} \mathrm{I}_{14}\right)(\mathrm{BV})_{2}\right]^{31}$ and they both directed by the same dication, the only difference is $\mathrm{Br}$ atom which from the structure-directing agent coordinates to $\mathrm{Pb}$ atom, the coordination environment of $\mathrm{Pb}$ has become more complicated. In packing structure, the anions moieties and cations counter cations held together by electrostatic interactions, as shown in figure $2 \mathrm{c}$ view along $c$ axis. The anions located in the 1D channel stacked by dications along $c$ axis.

\subsection{Power X-ray Diffraction (PXRD) and Thermogravimetric Analysis}

The experimental PXRD patterns of 1-2 correspond well to the simulated PXRD patterns, indicating that the bulk phase materials are isomorphous (Figure 3).

The TG curves of the two compounds are shown in figure 4. The TG data indicates that both of the two compounds were thermally stable up to $250^{\circ} \mathrm{C}$. The decomposition of $\mathbf{1}$ mainly proceeded in three stages. The first stage took place in the $45-252^{\circ} \mathrm{C}$ with $4.09 \%$ loss (calculated ratio $4.38 \%$ ), which corresponded to the elimination of solvent DMF molecule; the second stage in the $357-565^{\circ} \mathrm{C}$ with $19 \%$ loss (calculated ratio $25 \%$ ) mainly involved the removal of dication; The third stage of compound 1 in the $565-800^{\circ} \mathrm{C}$ mainly involved the extreme burning of inorganic framework. 
The TG data for 2 shows that the weight loss fast from 276 to $387^{\circ} \mathrm{C}$ with $23 \%$ loss (calculated ratio $21 \%$ ), and can be attributed to the loss of dication and some inorganic framework. Then the weight almost keeps constant. The second weight loss took place in the range $516-727^{\circ} \mathrm{C}$, which is ascribable to the further burning of mineral phase.

All in all, the thermal behavior of compounds $\mathbf{1}$ and $\mathbf{2}$ are similar and the loss of organic dications mainly happened near $350-380^{\circ} \mathrm{C}$, which means that the weak interactions in quantity of $\mathrm{CH} \cdots \mathrm{I} / \mathrm{Br}$ have limited influence on their thermostability.

\subsection{UV-Vis absorption}

The solid-state UV-Vis absorption spectra of 1-2 are presented in figure 5a. The absorption spectrum exhibits peak at $235 \mathrm{~nm}$ for $\mathbf{1}$ (236 nm for $\mathbf{2}$ ), which is the characteristic band of anions assigned as ligand-tometal charge-transfer $(\mathrm{LMCT})$ transition $(\mathrm{I} \rightarrow \mathrm{Pb})$. To explore the conductivity of compounds $\mathbf{1 - 2}$, the UVVis diffuse reflectance spectra of their powder samples were tested to obtain their band gaps $(E g)$ by using the Kubelka-Munk function. As shown in figure $5 \mathrm{~b}$. Their energy gaps $(E g)$ can be estimated as $2.35 \mathrm{ev}$ for $\mathbf{1}$ and $2.44 \mathrm{ev}$ for $\mathbf{2}$, respectively. There are tiny blue shifts of the energy gaps, $0.05 \mathrm{ev}$ for 1 and $0.14 \mathrm{ev}$ for 2, compared with that of bulk $\mathrm{PbI}_{2}(2.30 \mathrm{eV})$. The reflectance spectrum measurement revealed the nature of semiconductor.

\subsection{Template effect of title dication}

The use of organic species as templating agents has widened the number and nature of the microporous crystalline solid phases. ${ }^{32}$ The trapped organic moieties perform several roles: coulombic balance of the negatively charged framework; filling of the microporous cavities; structuring by the "template effect". Most significantly, the structural information from the organic template can be imprinted on the final supramolecular frameworks. ${ }^{33} \mathrm{~A}$ template is described as permanent ("internal") if all the molecular components originally present are also found in the end product. ${ }^{34} \mathrm{~A}$ recent interesting study showed that in the template effect of SDA, there exists rigidity/flexibility competition: To some extent, when the spacers are shorter the interaction energies are increased; otherwise, the interaction energies decreased. The rigidity/flexibility competition will achieve a balance at a proper point, at which the the most stable conformation can be presented. ${ }^{35}$
The title SDAs, 1, 4-PMBP and DBBP, were synthesised from 4, 4'-bipyridinium with 1, 4-bis (bromomethyl) benzene or benzyl bromide in a certain ratio and they are both $\pi$-conjugated 4,4 '-bipyridine derivatives dication templates, so the above rule will not be applicable. Single-crystal X-ray study revealed these two $\mathrm{PbI}_{2}$ compounds both contain incomplete cubane subunit and are similar 1D supramolecules. Compared with the reported molecules, most of them were synthetized directed by ethyl ammonium alkyl chain derivatives, ${ }^{11,21(b), 36} \pi$-conjugated dication template is rarely reported. Thus, we speculate that $\mathrm{PbI}_{2}$ prefers to form 1D supramolecule which possesses incomplete cubane subunit directed by $\pi$-conjugated dication templates. The studies described above provide initial evidence that the formation of supramolecule complex aggregating from the same initial material is highly dependent on the choice of guest. These novel supramolecule networks provide not only intriguing examples of modular chain-framework but also new insights into the regularity in construction of solid-state materials.

\section{Conclusion}

Two $\mathrm{PbI}_{2}$ hybrids are obtained via slow evaporation at room temperature from methanol and DMF system through dication templated self-assembly. As far as we know, compounds $\mathbf{1}$ and $\mathbf{2}$ can be regarded as 1D iodoplumbate examples with incomplete cubane subunit directed by $\pi$-conjugated dication templates. Hence, similar structured products would be obtained if we introduce similar templates. More importantly, this result provides us a new insight into the regularity in construction of solid-state materials.

\section{Acknowledgements}

We gratefully acknowledge the financial support by the National Natural Science Foundation of China (No. 21171148, J1210060) and The Graduate Student Self-innovation Project of Zhengzhou University (14LF00620).

\section{Supplementary Information}

Crystallographic data reported in this article have been deposited with the Cambridge Crystallographic Data Center as supplementary publication. CCDC numbers are 1032768 for $\mathbf{1}, 1032769$ for $\mathbf{2}$. These data can be obtained free of charge via http://www.ccdc.cam.ac.uk/ conts/retrieving.html (or from the Cambridge Crystallographic Data Center, 12 Union Road, Cambridge CB2 1EZ, UK; Fax: +44 1223336 033). 


\section{References}

1. Yaghi O M, Li H, Davis C, Richardson D and Groy T L 1998 Acc. Chem. Res. 31474

2. (a) Duan H B, Zhao H R, Ren X M, Zhou H, Tian Z F and Jin W Q 2011 Discuss. Faraday Soc. 40 1672; (b) Mishra S, Jeanneau E, Daniele S, Ledoux G and Swamy P N 2008 Inorg. Chem. 47 9333; (c) Chen Y, Yang Z, Guo C X, Ni C Y, Li H X, Ren Z G and Lang J P 2011 CrystEngComm. 13 243; (d) Mishra S, Jeanneau E, Iasco O, Ledoux G, Luneau D and Daniele S 2012 Eur. J. Inorg. Chem. 2012 2749; (e) Krautscheid H, Lode C, Vielsack F and Vollmer H 2001 J. Chem. Soc., Dalton Trans. 1099; (f) Tang Z J and Guloy A M 1999 J. Am. Chem. Soc. 121452

3. (a) Yu T L, An L, Zhang L, Shen J J, Fu Y B and Fu Y L 2014 Cryst. Growth Des. 14 3875; (b) Shen J J, Zhang C F, Yu T L, An L and Fu Y L 2014 Cryst. Growth Des. 146337

4. Blake A J, Champness N R, Hubberstey P, Li W S, Schrorder M, Withersby M and Schroder M A 1999 Coord. Chem. Rev. 183117

5. (a) Zheng Z, Yu Z P, Yang M D, Jin F, Ye L N, Fang M, Zhou H P, Wu J Y and Tian Y P 2014 Dalton Trans. 43 1139; (b) Jin F, Wang H Z, Zhang Y, Wang Y, Zhang J, Kong L, Hao F Y, Yang J X, Wu J Y, Tian Y P and Zhou H P 2013 Cryst. Eng. Comm. 153687

6. Sanchez C, Julian B, Belleville P and Popall M $2005 \mathrm{~J}$. Mater. Chem. 153559

7. (a) Wang M S, Xu G, Zhang Z J and Guo G C 2010 Chem. Commun. 46 361; (b) Pardo R, Zayat M and Levy D 2011 Chem. Soc. Rev. 40672

8. Wang G E, Jiang X M, Zhang M J, Chen H F, Liu B W, Wang M S and Guo G C 2013 Cryst. Eng. Comm. 15 10399

9. Vincent B R, Robertson K N, Cameron T S and Knop O 1987 Can. J. Chem. 651024

10. (a) Dobrzycki L and Woźniak K 2008 Cryst. Eng. Comm. 10 577; (b) Dobrzycki L and Woźniak K 2009 J. Mol. Struct. 92118

11. Krautscheid H and Vielsack F 1999 J. Chem. Soc. Dalton Trans. 242731

12. Yue J M, Niu Y Y, Zhang B, Ng S W and Hou H W 2011 Cryst. Eng. Comm. 132571

13. Cuna A, Aguiar I, Gancharov A, Pérez M and Fornaro L 2004 Cryst. Res. Technol. 39899

14. Wang S, Mitzi D B, Feild C A and Guloy A 1995 J. Am. Chem. Soc. 1175297

15. Billing D G and Lemmerer A 2006 Cryst. Eng. Comm. 8686

16. Wang G E, Xu G, Wang M S, Sun J, Xu Z N and Guo G C 2012 J. Mater. Chem. 2216742

17. Wang C H, Ma C J, Huang Z P, Zai Y X, Yang Q, Li L and Liang Y 2015 J. Clust. Sci. 261027
18. (a) Calabrese J, Jones N L, Harlow R L, Herron N, Thorn D L and Wang Y $1991 \mathrm{~J}$. Am. Chem. Soc. 113 2328; (b) Mitzi D B 1996 Chem. Mater. 8 791; (c) Zhu X H, Mercier N, Riou A, Blanchard P and Frère P 2002 Chem. Commun. 2160; (d) Mercier N 2005 Cryst. Eng. Comm. 7 429; (e) Billing D G and Lemmerer A 2008 New J. Chem. 321736

19. (a) Corradi A B, Ferrari A M, Pellacani G C, Saccani A, Sandrolini F and Sgarabotto P 1999 Inorg. Chem. 38 716; (b) Corradi A B, Ferrari A M, Righi L and Sgarabotto P 2001 Inorg. Chem. 40218

20. Dobrzycki L and Woźniak K 2008 Cryst. Eng. Comm. 10525

21. (a) Zhang Z J, Xiang S C, Guo G C, Xu G, Wang M S, Zou J P, Guo S P and Huang J S 2008 Angew. Chem. Int. Ed. 47 4149; (b) Krautscheid H, Lekieffre J F and Besinger J 1996 Z. Anorg. Allg. Chem. 6221781

22. Fan L Q, Huang Y Z, Wu L M, Chen L, Li J Q and Ma E 2006 J. Solid State Chem. 1792361

23. Mercier N and Riou A 2004 Chem. Commun. 844

24. Billing D G and Lemmerer A 2009 Cryst. Eng. Comm. 111549

25. Wang G E, Wang M S, Jiang X M, Liu Z F, Lin R G, Cai L Z, Guo G C and Huang J S 2011 Inorg. Chem. Commun. 141957

26. (a) Billing D G and Lemmerer A 2007 Cryst. Eng. Comm. 9 236; (b) Shan Z M, Wang Y L, Guo H X, Liu Q Y, Zhang N, Yang E L and Li L Q 2011 Inorg. Chim. Acta. 366141

27. Geudhr W, Hunig S and Suchy A 1986 Tetrahedron 42 1665

28. Higashi T and Sagara T 2013 Electrochimica Acta 114 105

29. Sheldrick G M 1997 SHELXTL-97, Program forCrystal Structure Refinement, University of Gottingen, Germany

30. Papavassiliou G C, Mousdis G A, Raptopoulou C P and Terzis A 1999 Z. Naturforsch. B. 541405

31. Chen Y, Wang Z O, Yang Z, Ren Z G, Li H X and Lang J P 2010 Dalton Trans. 399476

32. (a) Soler-Illia G J D A A, Sanchez C, Lebeau B, Patarin J 2002 Chem. Rev. 102 4093; (b) Huo Q, Margolese D I, Ciesla U, Demuth D G, Feng P, Gier T E, Sieger P, Firouzi A and Chmelka B F 1994 Chem. Mater. 61176

33. (a) Alexander K L, Yuen F H, Antony J W, Antony F M and Thomas M 2012 Microporous Mesoporous Mater. 148 62; (b) Li H H, Chen Z R, Li J Q, Huang C C, Zhang Y F and Jia G X 2006 Eur. J. Inorg. Chem. 122447

34. Hoss R and Vogtle F 1994 Angew. Chem. Int. Ed. 33375

35. Li H H, Xing Y Y, Lian Z X, Gong A W, Wu H Y, Li Y and Chen Z R 2013 Cryst. Eng. Comm. 151721

36. Krautscheid H and Vielsack F 1997 Z. Anorg. Allg. Chem. 623259 